\title{
Romantic Narrative in the Film The Battle at Lake Changjin
}

\author{
Mao Feng, \\ Lyu Wenhui, \\ Yang Xinle, \\ Wu Biyu
}

\begin{abstract}
Chen Kaige, a famous Chinese "scholar-type director", usually contains rich cultural connotations in his films and his works are always full of Chen Kaige-style romanticism. Although he is good at narrative, making The Battle of Changjin Lake a pure war film is a challenge. Therefore, this article takes the film as the research focus. The analysis of aesthetic elements, such as scenes and scope, picture composition, color and so on, expounds into detail the narrative style of romanticism displayed by Chen Kaige in the film.
\end{abstract}

\section{Keywords}

The Battle at Lake Changjin; Romantic Narrative; Aesthetics; Color; Scenes 


\title{
Romantic Narrative in the Film The Battle at Lake Changjin
}

\author{
Mao Feng \\ Lyu Wenhui \\ Yang Xinle
}

Wu Biyu

\section{Introduction}

One month or so has passed since China's National Day, but the box office of the movie The Battle at Lake Changjin did not stop because of the holiday. On the contrary, it has made great progress and rapidly exceeded 5.5 billion. Firstly, many viewers thought Chen Kaige, one of the three Chinese directors who co-directed, is not good at making a war film with such a big scene as The Battle at Lake Changjin. Chen Kaige is good at shaping the emotional narration of movies. In his directing career, there is no outstanding work about war. However, the success of the pure war film Battle of Changjin Lake on National Day made Chen Kaige create greater glories and completely tore off the label of "Cheng Dieyi", one of the famous film characters he created.

\section{Narrative Aesthetics of Chinese Military Films in the New Era}

During the development of Chinese military-themed films, directors have been committed to seeking breakthroughs and innovations in narrative forms. Most Chinese military-themed films in the new era are adapted from real events in history (Zhang 146). The stories presented in the films are derived from real events and belong to the category of non-fiction, literary, and artistic creations (Mengya 140). Before the audience enters the movie theater to watch the movie, they already have some understanding of the historical facts, and they have their construction of the causes and consequences of historical events and the development context. This requires the content of the movie not to deviate from the basic historical facts. The refreshing feeling meets the expectations of the audience, to obtain a fresh aesthetic feeling. Changjin Lake is no exception. Based on respecting historical facts, director Chen Kaige gives the audience a new aesthetic 
experience in narrative from different angles and with the help of diversified means. From the perspective of film narratology, director Chen Kaige's narrative aesthetics does not only offer a self-contained aesthetic experience but also an innovation in film narrative.

\section{Chen Kaige's Narrative Aesthetics}

As one of the representatives of China's fifth-generation directors, Chen Kaige's films have attracted wide attention. Chen Kaige is good at enhancing emotional narration through the use of theme music, in-picture music, and sound tones in films (Tong and Hongjun 138). He often creates unique visual enjoyment with poetic language, breaks through the traditional narrative norms, and strongly expresses his self-consciousness and aesthetic ideal (Shiliu and Ying 116). Chen Kaige also often integrates Peking opera into movies(Dongmei 131), expresses emotions and philosophies from the perspective of visual space and color (Zhihong and Feng 68; Lizhen 59). Somescholars also argue that Chen Kaige's aesthetic appreciation of movies has gradually changed from elite consciousness to commercial consciousness (Huan 38), and they have different views. This study holds that Chen Kaige's narrative aesthetics in his films can be reflected in the following three aspects.

Firstly, this film makes good use of picture composition. The beauty of the film is not only from the lightbut also from the composition. The overall composition of the film always gives the audience a visual impact at the first time. Excellent picture composition plays an extremely important role in realizing the aesthetic value of movies. Director Chen Kaige's film composition is an important feature of his "film-philosophy". He often chooses to find another way in composition, often compares grand landscapes with small characters to highlight the theme of the film. For example, in the movie Yellow Land, the ratio of characters to the vast plateau is extremely distorted, which brings a strong sense of oppression to the audience. In addition, he also makes good use of the 'golden section' rule in movies to give the audience a balanced picture, which accords with human aesthetic experience. For example, the film The Promise directed by Chen Kaige used the composition method of "Golden Rule", which brought an unparalleled visual feast to the audience.

Second, this film uses scenery and angles skillfully. Chen Kaige makes good use of different shooting angles, and alternately uses distant views and close-ups, which endows the whole movie with dynamic and static beauty. He is also good at using candlelight, lighting, sunlight, and other bright and dark contrasts to guide the audience's sight and using light as a metaphor for the theme of the movie. In his representative work Biography of the Demon Cat, a lot of techniques have been applied to the shooting. For example, at the imperial concubine's birthday party, three-quarters of Chen Kaige's composition is the sky, the scenery changes from time to time, people remain the same, and theimperial concubine swings on the swing, further highlighting the beauty of Yang Yuhuan's postureand the prosperity of Tang Dynasty.

Thirdly, this film uses rich color language. Color, like sound and composition, can 
directly convey information and express feelings (Quero et al. 4). Pursuing the ultimate enjoyment of the senses is the most prominent feature of Chen Kaige's poetry aesthetics. Similarly, the movie The Legend of the Demon Cat reflects his bold use of color. In other films, we can also see his free control of color, giving people the ultimate visual enjoyment. Different from the gorgeous Biography of Demon Cat, The Yellow Land is quite dull in color, in sharp contrast with rural girl Cui Qiao's red coat, which symbolizes the protagonist's inner pursuit and tragic fate.

That is, taking the movie Battle of Changjin Lake, which hits in 2021, as an example, combined with Chen Kaige's narrative aesthetics, especially the use of color to express the theme of a war film. Its influence on people's psychological activities and its visual impact, this paper discusses the romantic narrative style and philosophy in Chen Kaige's movies in detail.

\section{Aesthetics and the Expression of Movie Theme}

With the gradual maturity of the application of art color in movies, its role is not only to enrich the movie picture but also to express the theme and spirit of the movie (Xuan 44). The theme of the film can no longer only be expressed through the story, but the application of color, picture composition, light, and shadow, which can also show the central idea of the film to the audience from different dimensions. Many viewers were impressed by the scene of "Soldier Wu Qianli's Home" in The Battle at Lake Changjin's first play. At the beginning of the film, a picture of a water town in the south of the Yangtze River is depicted. On the riverbank, a leaf boat forms a typical Chinese landscape painting with the distant green hills and clear waters, the vast sky, and the yellow lights of fishing boats. The blue-green of the lake, the green of trees, the blue of the sky, and the light yellow of the military uniform are used to render the scene in warm tones throughout the whole period, with rich colors but low saturation, which brings the audience a comfortable feeling. This kind of peace after the war and the warmth of hometown are exactly what the people in the war at that time expected, which implies the theme of the movie "defending the country". In the first part of the film, the depiction of beautiful hometown, frolicking between brothers and a happy family reunion paved the way for the latter "defending the country", which reflects the great spirit of Chinese soldiers "giving up their homes for everyone". Similarly, this "landscape painting" full of artistic conception reflects director Chen Kaige's profound attainments in film picture composition. Clever division of picture composition is also an important part of freehand brushwork presentation in movies (Mingyan 75). In the scene of Wu Qianli's homecoming, Chen Kaige used the concentric composition method. The subject is located in the middle of the picture, and the scenery is concentrated from all sides to the center. Wu Qianli, dressed in a light yellow military uniform, was surrounded by green hills, and the audience's eyes were naturally guided to Wu Qianli. Different from the sense of suffocation and depression shown by the vast plateau as the protagonist of the painting in The Yellow Land, this picture in The Battle at Lake Changjin puts people in the dominant position, and the proportion between man and nature is coordinated. Although it highlights the character Wu Qianli, it will not make people ignore the beautiful mountains behind him, and can also convey the idea of 
harmony between man and nature.

Classical long-lens theory emphasizes the restoration of space and time in the real world, and its essence lies in realistic expression by the objectivity of the long-lens (Tong and Hongjun 146). In the scene of Wu Qianli's returning to his hometown, Wu Wanli runs on the ridge in his hometown, using a long lens. The long-shot changed scenery with the runner $\mathrm{Wu}$ Wanli. This scene showed the scenery in the south of the Yangtze River in a documentary way, and the fishing village is quiet and peaceful. In addition, the deep temperament of the long lens is lyrical, and the long lens can magnify the emotions and expressions of the characters. Wu Wanli faltered at a trot from the beginning, then ran frantically, and finally the joy that his brother's coming home. On the orders of $\mathrm{Wu}$ Qianli's Corps, he left his hometown to continue fighting. At this point, a vision opens up. Wu stood on the boat, lights on fishing boats in the distance, and therewas a full moon hanging in the air, with bright contrast between light and shade. The Mid-Autumn Festival, a Chinese traditional reunion festival, is supposed to be reunited, but now it's time to leave. The application of this vision properly describes the fearless spirit of Chinese soldiers who obey the Party's command, love the country, and take care of the overall situation in all actions.

\section{Aesthetics and the Structure of the Inner World of Characters}

The most direct way to show the inner world of a character in a movie is to use his words and deeds or narration. However, if all the psychological activities of the character are reflected in the above-mentioned way in the whole movie, it will inevitably be slightly monotonous and boring, and then the unique advantages of expressing the psychological state of the characters through color will be revealed. The director can link the objective images in the film with the psychological activities of the characters through the design of some picture colors in the film, and express the changes of the inner activities of the characters so as to achieve the effect of "arriving at the point of view surreptitiously" (Xia 159). Everyone believes that the moment when the Great Wall in The Battle of Changjin Lake came into view, it must have left a deep visual impact to the audience. The colorful Great Wall, one of the most famous Chinese wonders in the world, is the "scheming" of director Chen Kaige. In the movie, "Seventh Company" takes a train from the south to the north. On the train, Wu Wanli is a very individual child. When accepting the ceremony of giving guns to recruits, he can't stand his comrades-in-arms to teasing him, so he loses his temper and wants to jump on the train. At the moment of opening the door, the winding Great Wall appears in the splendid light of the sky, and $\mathrm{Wu}$ Wanli is stunned. At that moment, he realized that his motherland is so charming, and he is determined to "defend his country", realizing the transformation from a wild boy to a real soldier. In this romantic segment, the director uses poetic shooting horizon to show the sublimation of characters' psychological consciousness and makes full use of the special role of color in film narrative.

In Chen Kaige's films, we can feel the strong characteristics of the eastern geo- 
culture and times (Mingyan 74). Symbolic composition often relies on close-up images to strengthen the behavior of characters or parts of objects, thus endowing the subject with symbolic meaning and enhancing metaphorical colors so that the images seen by the audience are far larger than the real space (Xiaobing 150). As the totem of the Chinese nation, the Great Wall is a symbol of will, courage, and strength. When the camera is switched from the train to the Great Wall, the magnificent scene comes into view, the mountains and rivers unattacked. This "poetic scene" of the Great Wall vividly interprets Chen Kaige-style romance. The Great Wall looks like an oil painting. Chen Kaige uses a large area of cool colors such as black, gray and brown, supplemented by warm colors such as orange and red, and achieved a change of cool and warm in hue and contrast of major and minor in color so that the scene shows a contrast between real and unreal scenes, creating a peaceful and quiet atmosphere.

\section{Aesthetics and the Embodiment of Characters' Emotions}

Color has a strong visual impact, and every color in China has been given different meanings since ancient times (Shiliu and Ying 117). Red is a very ancient color that became popular as early as the Zhou Dynasty and is of great significance to the Chinese people. Red is the color of the modern Chinese flag, representing the warmth, bravery, exuberance, passion, and fighting spirit of the Chinese people, so the meaning of red is very diverse and will be given different meanings in different situations. In Chinese traditional weddings, it expresses joy and excitement. In war, it expresses depression and tragedy. Chinese people have profound ethnic feelings about red. Chen Kaige is remarkable in the use of color, that is, he is very good at using red. In the Emperor's Wedding scene, his concubine is dressed in a red costume, etc. In The Yellow Land, protagonist Cui Qiao's wedding is red and black, which shows the depressive feeling of this wedding to the page. In terms of color configuration, the red scarf in The Battle at Lake Changjin reflects Chen Kaige's unique views on love and war. The red scarf first appeared in the Seventh Company taking the train to the Korean battlefield. When passing through the depot, due to the bombing of the US military, it was not possible to carry the cold-proof materials in time. A female soldier took off her red scarf and threw it into the train compartment and $\mathrm{Wu}$ Wanli took it. This kind of color contains the young $\mathrm{Wu}$ Wanli's yearning for love. In addition, the film combines red with large areas of yellow, black, and brown, which makes people feel the tension and pressure from the wind and rain, and shows the hardships and huge casualties of the battle of Changjin Lake. The red color here also represents the national spirit that Chinese soldiers are not afraid of bloodshed and sacrifice. In terms of color switching, the film outputs the emotions of the characters, renders the atmosphere of the film, conveys the symbolic significance and forms a good emotional communication with the audience. 
Chen Kaige's use of red in this film is undoubtedly successful. He did not use too many scenes to describe the love hidden in the red scarf. He just used a color contrast to bring a shock to people's vision, but it can make people realize the profound cultural and historical and humanistic background behind this color (Shiliu and Ying 117).

The ice sculpture at the end of the film made countless viewers cry. On the one hand, we can see the fearless heroism of Chinese soldiers; on the other hand, we can also see that Chen Kaige combines the cool blue with the emotions of the audience. We can believe the fact that the sky is always blue. So blue is often synonymous with concepts of loyalty and trust. Blue will show some seemingly contradictory features because it is the coldest color in the chromatogram. Its subtle changes will make you have completely different emotional reactions (Pingfan 145). Rows of volunteer soldiers, lying at minus 40 degrees Celsius, armed with steel guns and grenades, kept a neat formation and fighting posture as if they were a group of "ice sculptures". The blue color expressed the shock, coupled with the sad after taste, and showed Chen Kaige's superb technology in the application of color.

\section{Conclusion}

Aesthetics in the films directed by Chen Kaige is very romantic, and Chen Kaige also combines aesthetics with narration to a nicety word choice that brings a visual feast to people. With the maturity of aesthetics in film application, its function has gradually changed from simply enriching the film pictures to expressing the theme and spirit of the film. First, the color, composition, and narrative theme are skillfully combined romantically. Secondly, in shaping the characters' minds, aesthetics is not as direct as action and narrative. It can moisturize things in silence to the heart and show the changes in people's mental activities. Finally, aesthetics can express the strong emotional changes of characters and pass them on to the public. In The Battle of Changjin Lake, the composition of ships, rivers, the Great Wall, and autumn scenery is beautiful, and these scenes are all to be compared with the cruel battlefield. In this regard, Director Chen Kaige remarked that it is for comparison with the following war. If there are no words about peace, then we cannot feel that the destruction of war on peace is so strong.

\section{Works Cited}

Dongmei, Ma. "Aesthetics and Symbolism in Chen Kaige's films." Movie Literature, no. 01, 2015, pp. 81-83. CNKI, https://doi.org/10.3969/j.issn.0495$\underline{5692.2015 .10 .027}$

Huan, Zhang. "The Color Art Construction in the Film Legend of the Demon Cat." Movie Review, no. 08, Apr. 2018, pp. 36-38. CNKI, 
https://doi.org/10.16583/j.cnki.52-1014/j.2018.08.010

Lizhen, Zhang. "The Application of Traditional Opera Aesthetics in Chen Kaige's

films." Movie Literature, no. 05, May. 2016,pp. 58-60. CNKI,

https://doi.org/10.3969/j.issn.0495-5692.2016.05.019

Mengya, Li. "Narrative Aesthetics of Chinese Military Movies in the New Era."

Literature and Art Criticism, no. 04, Apr. 2021, pp.120-128. CNKI, https://doi.org/10.16566/j.cnki.1003-5672.2021.04.014

Mingyan, Wang. "Legend of the Demon Cat and the Aesthetic Turn of Chen Kaige

Films." Movie Literature, no. 04, Feb. 2019, pp. 73-75. CNKI,

https://doi.org/10.16583/j.cnki.52-1014/j.2018.03.010

Pingfan, Ren. "Analysis on the Aesthetic Characteristics of Chen Kaige's Films." Home Drama, no. 31, 2020, pp. 144-146. CNKI, https://doi.org/10.3969/j.issn.1007-0125.2020.11.067

Quero, Luis, et al. "Multi-Sensory Color Code Based on Sound and Scent for Visual Art Appreciation.” Electronics, vol. 10, no. 14, 2021, p. 1-27. https://doi.org/10.3390/electronics10141696

Shiliu, Tong, Ying, Shi. “The Music on Chen Kaige's Movies.” Contemporary

Cinema, no. 12, Dec. 2011, pp. 114-118. CNKI, https://kns.cnki.net/kcms/detail/detail.aspx?FileName=DDDY201112036\& $\underline{\text { DbName }=\text { CJFQ2011 }}$

Tong, Cao, Hongjun, Cao. "From Simulation to Hallucination -An Aesthetic Study on 'One-Shot Feature Film.'". Journal of China University of Mining \& Technology (Social Sciences), vol. 24, no.01, Nov. 2021, pp.137-148. CNKI, http://kns.cnki.net/kcms/detail/32

Wang Xuan. "On the Poetic Philosophy and Artistic Expression in Kaige Chen's Films." Movie Review, no. 03, Feb. 2018, pp. 43-45. CNKI, https://doi.org/10.16583/j.cnki.52-1014/j.2018.03.010

Wang Zhihong, Li Feng. "The visual space structure in Chen Kaige's films." Movie Literature, no. 18, Sep. 2016, pp. 67-69. CNKI, https://doi.org/10.3969/j.issn.0495-5692.2016.18.022

Xiaobing Guo. "Interpretation of the Relationship Color and Film Narrative Time and Space". Movie Literature, no. 05, 2014, pp. 150-151. CNKI, https://doi.org/10.3969/j.issn.0495-5692.2014.05.074

$\mathrm{Yu}$, Xia. "Appreciation of Art Color in the Assembly." Movie Literature, no. 01, 2014, pp. 158-159. CNKI, https://doi.org/10.3969/j.issn.0495-5692.2014.01.076

Zhang, Huiyu. "Chinese Blockbusters and Culture Self-Confidence." Javnost-The Public, vol. 27, no.2, 2020, pp. 140-153. https://doi.org/10.1080/13183222.2020.1727272 


\section{Mao Feng}

\section{The Authors}

Associate Professor, School of Foreign Languages, Shanghai University of International Business and Economics, Shanghai, China.

Email: maofeng@suibe.edu.cn

\section{Lyu Wenhui}

School of Foreign Languages, Shanghai University of International Business and Economics, Shanghai, China.

\section{Yang Xinle}

School of Foreign Languages, Shanghai University of International Business and Economics, Shanghai, China.

\section{Wu Biyu}

Professor, School of Foreign Languages, East China University of Science and Technology, Shanghai, China.

Corresponding Author, Email: 13166212097@163.com

\section{The Article}

Date Sent: 08/01/2022

Date Revised: 14/02/2022

Date Accepted: 18/02/2022 